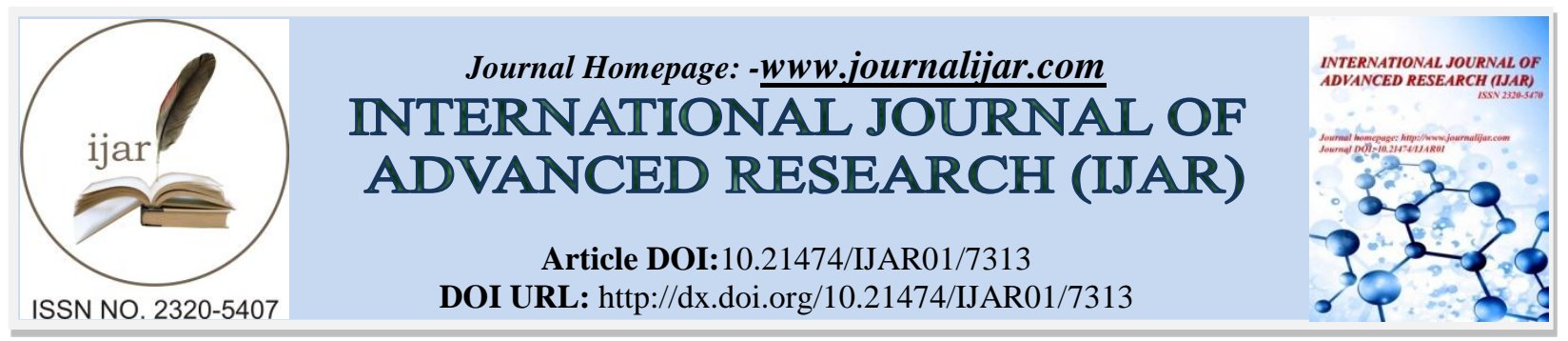

RESEARCH ARTICLE

\title{
ATTENUATION OF HEMODYNAMIC RESPONSES TO ENDOTRACHEAL INTUBATION: COMPARISON OF CLONIDINE AND ESMOLOL.
}

Anuradha Swaminathan.

M.d, d.a.madras medical college, chennai.

\section{Manuscript Info}

Manuscript History

Received: 18 April 2018

Final Accepted: 20 May 2018

Published: June 2018

\section{Keywords:-}

clonidine, esmolol, hemodynamic, intubation

\section{Abstract}

Objective: The objective of the study was to compare the effects of esmolol with those of clonidine on the prevention of tachycardia and hypertension caused by endotracheal intubation.

Methods: This was a prospective, randomised, double-blinded study. The patients were randomised into two equal groups. The esmolol group (group E) received esmolol $1 \mathrm{mg} / \mathrm{kg}$ and the clonidine group (group C) a received clonidine $2 \mathrm{mcg} / \mathrm{kg} 2$ minutes prior to endotracheal intubation. Heart rate (HR), mean arterial pressure (MAP) and rate pressure product (RPP) were recorded before and after induction of anaesthesia, immediately after intubation and 1, 3, 5, 7 and 10 minutes after intubation.

Results: Patients in group $\mathrm{C}$ showed the maximum attenuation of both heart rate and blood pressure following endotracheal intubation. Patients in group E showed a significant attenuation of heart rate as effective as group $\mathrm{C}$ but attenuation of blood pressure was not as effective as group C.All the patients were recovered well from anaesthesia and none of them developed complications like severe bradycardia( HR $<50 / \mathrm{min}$ ) or profound hypotension( $\mathrm{SBP}<80 \mathrm{mmHg}$ ).

Conclusion: From the above study it is concluded that the hemodynamic changes associated with endotracheal intubation can be safely and effectively obtunded by using intravenous clonidine $2 \mathrm{mcg} / \mathrm{kg}$ prior to induction of anaesthesia. Clonidine is found to be effective in blunting hemodynamic responses to laryngoscopy and intubation, followed by esmolol $1 \mathrm{mg} / \mathrm{kg}$.

Copy Right, IJAR, 2018,. All rights reserved.

\section{Introduction:-}

The hemodynamic responses to laryngoscopy and endotracheal intubation have been recognised since 1951. Induction of anaesthesia, laryngoscopy, tracheal intubation and surgical stimulation often evoke cardiovascular responses characterised by alteration in systemic arterial blood pressure, heart rate and cardiac rhythm. The response following laryngoscopy and intubation peaks at 1.2 minutes and return to baseline within 5 to 10 minutes.

Though the sympathoadrenal responses are probably of little consequence in health patients, it is hazardous to those patients with hypertension, coronary heart disease, cerebrovascular disease, intracranial pathology and hyperactive 
airways. In such cases, reflex circulatory responses such as an increase in heart rate, systemic arterial pressure and disturbances in cardiac rhythm need to be suppressed.

Prof King et al (1951) documented myocardial ischemic changes due to reflex sympathoadrenal responses immediately following laryngoscopy and intubation with a mean increase in systolic pressure of 40mmhg even in normotensive individuals. Pyrs Roberts et al, (1971) showed exaggerated form of this response in hypertensive patients. Various systemic as well as topical agents have been used to reduce these untoward hemodynamic responses during laryngoscopy. When compared to systemic agents, administration of local anaesthetic solutions are likely to be of limited value. The commonest strategies adopted are narcotics, vasodilators, $\beta$-blockers, calcium channel blockers, lignocaine, clonidine and other sympatholytics. In our study, we have compared esmolol and clonidine in suppressing stress responses to laryngoscopy and intubation.

\section{Aim Of The Study:-}

For the safe conduct of anaesthesia, the hemodynamic responses to laryngoscopy and intubation should be abolished or at least attenuated to balance the myocardial oxygen supply and demand. This study was done to compare the efficacy of intravenous clonidine and esmolol in attenuating the hemodynamic stress responses to laryngoscopy and intubation.

\section{Materials And Methods:-}

One hundred and twenty patients of ASA physical status 1 or 2 undergoing elective surgical procedure under general anaesthesia with endotracheal intubation were included in this study.

Patients belonging to age group 15 to 60 years of both the sexes were included. It is a prospective randomized controlled study. The study was approved by our institution ethical committee and after obtaining written, informed consent from the patient, this study was conducted.

The study was done during the period from april 2018 to may 2018 in the Department of Anaesthesiology, Govt. General hospital, Chennai 3.

\section{Inclusion criteria:-}

1. ASA 1 or 2 .

2. Patients with airway with modified mallampati grade class 1 or 2 .

3. Age group 15 to 60 years of both sexes.

\section{Exclusion criteria:-}

1. Patients with full stomach.

2. Patients posted for emergency surgery.

3. Patients with difficult airway.

4. Hypertension, diabetes, ischemic heart disease and pregnancy.

5. Patients with contraindications to study drugs.

6. Patient refusal.

\section{Materials:-}

1. Injection thiopentone $2.5 \%$ solution

2. Injection suxamethonium

3. Injection glycopyrollate

4. Injection fentanyl

5. Injection esmolol hydrochloride( esocard) $100 \mathrm{mg} / 10 \mathrm{ml}$ vial

6. Injection clonidine $0.15 \mathrm{mg} / \mathrm{ml}$ ampoule

7. Normal saline

8. Disposable $10 \mathrm{ml}$ syringe

9. Laryngoscope with blades 3 and 4

10. Endotracheal tubes of various sizes.

\section{Pre anaesthetic preparations:-}

All the patients were admitted and they underwent routine investigations like:

1. Hemogram 
2. Blood urea and sugar

3. Serum creatinine and electrolytes

4. Chest X-ray

5. Electrocardiogram

Other investigations were obtained on the basis of the condition of the patient.

\section{Anaesthetic protocol:-}

Pre-operative visit was done to allay anxiety and good rapport was established with the patients. All the patients were given pre-operative night sedation with tab.alprazolam $10 \mathrm{mg}$ orally.

\section{Interventions:-}

Induction of anasesthesia was standardised for all patients. Monitors used were NIBP, ECG. Et co2 and pulse oximetry.

\section{Method:-}

One hundred and twenty patients of both the sexes of ASA 1 or 2 undergoing surgical procedure were randomly allocated into two groups.

Group C (clonidine $2 \mathrm{mcg} / \mathrm{kg}$ ) - 60 patients were given intravenous clonidine $2 \mathrm{mcg} / \mathrm{kg} 2 \mathrm{minutes}$ before induction. Group E (esmolol 1mg/kg) - 60 patients were given intravenous clonidine $1 \mathrm{mg} / \mathrm{kg} 2$ minutes before induction.

\section{Premedication:-}

Patients are shifted to the operating table. Their pulse rate, blood pressure and sp02 were recorded. They were premedicated with injection glycopyrollate $4 \mathrm{mcg} / \mathrm{kg}$ body weight intravenously and injection fentanyl $2 \mathrm{mcg} / \mathrm{kg}$ body weight intravenously. Then, their heart rate, blood pressure and sp02 were recorded.

\section{Preoxygenation:-}

It is done with $100 \%$ oxygen for 3 minutes.

\section{Administration of study drug:-}

The study drug was taken in a $10 \mathrm{ml}$ syringe in a diluted form and given in bolus over 10 to 15 seconds. Then vital signs were recorded Two minutes later, patient was induced with injection thiopentone $2.5 \% 5 \mathrm{mg} / \mathrm{kg}$ body weight intravenously. Then, injection succinylcholine $1.5 \mathrm{mg} / \mathrm{kg}$ body weight was given. Intubation was performed by the same person for all the cases with appropriate sized endotracheal tubes orotrachealy.

Anaesthesia was maintained with controlled ventilation with $\mathrm{N} 20 / 02$ mixture $2: 1$ and injection atracurium $0.5 \mathrm{mg} / \mathrm{kg}$ given as initial dose. No surgical stimulation was permitted for 5 minutes after intubation

Patients were monitored throughout the period from entering into operation theatre till recovery and in the immediate post operative period by means of automated NIBP, pulse oximetry and ECG in a multichannel monitor. ECG was monitored with particular importance to any alteration in rhythm. All patients were extubated and were shifted to post anaesthetic care unit for a follow up for 24 hours. Results were tabulated and analysis done by 't' test. A p - value of less than 0.05 was considered as statistically significant

\section{Discussion:-}

Laryngoscopy and endotracheal intubation produces hemodynamic responses characterized by hypertension and tachycardia. This neuroendocrine responses can cause a variety of complications in patients with carciac disease due to imbalance of myocardial oxygen supply and demand like ischemic changes, ventricular arrythmias and cardiac failure.

This is also hazardous in patients with vascular pathologies due to weakening of lining of major arteries in particular cerebral and aortic aneurysms. In patients with hydrocephalus or intracranial mass lesions the increase in CSF pressure may produce transient impairment of cerebral perfusion leading to cerebral ischemia. 
These reflex responses may be diminished or modified locally or centrally and attempts have been made to accomplish this with varying sucess by different techniques and agents. No effective drug has been found out so far to abolish this response totally.

Many drugs have been reported to have beneficial effects in partially attenuating sympathoadrenal respenses to endotracheal intubation. Injection esmolol, fentanyl, calcium channel blockers have been extensively studied by many authors. Alpha 2 agonist clonidine, though not extensively studied like other drugs, there are many reports stating its theneticial eflects in attenuatien of eireulatory responses to endotracheal intubation.

Batra VK, Inadu B, Puri GD et al., in 1088 studied the attenuation of circualatory responses to laryngoscopy and intubation by oral clonidine $(5 \mathrm{meg} / \mathrm{kg}$ ) and concluded dat oral clonidine does circumvent the response. This study result added more supports to earlier studies conducted by Ghignone et al, and Poutu et al in 1987. Carabine et al compared different doses of itravenous clonidine in attenuating intubating responses in 1991. Zalunardo et al compared intravenous clonidine with intravenous esmolol in attenuating intubation responses and found out that intravenous clonidine $[3 \mathrm{mcg} / \mathrm{kg}$ ] iv was statistically significant ( $\mathrm{p}$ value 0.05 ) in attenuating intuabation responses compared to intravenous esmolol ( $2 \mathrm{mg} / \mathrm{kg}$ iv).

In our study comparison of intravenous clonidine $(2 \mathrm{mcg} / \mathrm{kg})$ and esmolol $(1 \mathrm{mgkg})$ was done in attenuating circulatory responses to endotracheal intubation. The data was analysed using Microsoft Excel, and SPSS 10.0 for windows. Haemodynamic variables were represented by mean+-SD. Statistical significance in mean difference was assessed by the use of one way analysis of variance. Tukey's HSD was applied to evaluate inter group comparisons. A p value of 0.05 was considered as statistically significant.

\section{Heart Rate changes:-}

The baseline mean heart rate of the two groups did not have any statisticaly significant differences as their $\mathrm{p}$ value was 0.055 . At the time of induction also there was no significant difference in mean heart rate among the two groups $\mathrm{P}$ 0.080. Once endotracheal intubation was performed, there was a rise in heart rate in both groups, of which the rise in heart rate in group $\mathrm{C}$ was found to be least when compared to group $\mathrm{E}$. Though the rise in heart rate in group $\mathrm{C}$ is lowest, it is statistically insignificant when compared to group $\mathrm{E}$ ( $\mathrm{p}$ value 0.068 ). Our study results with regard to heart rate matches with Vucevic et al which proved efficacy of esmolol and Carabine et al which proved the efficacy of clonidine. The heart rate in group $\mathrm{C}$ stayed significantly lower than group $\mathrm{E}$ even at 5 minutes after intubation ( $\mathrm{p}$ value 0.001). Thus it is inferred that though clonidine and esmolol are equally eflective in blunting rise in heart rate immediately following intubation. Clonidine provides a better hemodynemic stability than esmolol for a longer duration following intubation.

\section{Systolic blood pressure changes:-}

There was no significant difference in baseline systolic blood pressure values (p 0.137) among the two groups. Even at induction, there was no difference in systolic blood pressure of the two groups $(\mathrm{p}=0.650)$ after intubation there was a sudden increase in systolic blood pressures in both the groups. Group C had a least rise in systolic blood pressure which when compared with group $E$ was statistically significant ( $\mathrm{p}$ value 0.007 ). Even after 5minutes group $\mathrm{C}$ differed from group $\mathrm{E}$ by showing a sustained attenuation of pressor response. Attenuation of pressor response by group E in our study matches with studies conducted by Yuan et al., Chings et al. and Helfman et al. The difference between group $\mathrm{C}$ and group $\mathrm{E}$ matches with study conducted by Zulandaro MP et al in 2001 which proved clonidine was more effective than esmolol in attenuating pressor response to endotracheal intubation.

\section{Diastolic and mean arterial pressure changes:-}

There was no significant difference in baseline diastolic blood pressure among the two groups ( p-0.087) and also in baseline mean arterial pressure ( $\mathrm{p}$ 0073). During induction of anaesthesia, the groups did not show significant difference in diastolic blood pressure or mean pressure. After intubation, there was a sudden increase in diastolic and mean arterial pressures in both the groups. Group $\mathrm{C}$ had least rise in diastolic blood pressure and mean arterial pressure which when compared with group E were statistically significant ( $\mathrm{p}$ vaule being 0.006 and 0.009 arterial respectively). Even after 5minutes, group $\mathrm{C}$ differed from group $\mathrm{E}$ showing a sustained attenuation of pressor response. At 3 minutes and 5 minutes, there was no statistically significant difference in both diastolic blood pressure and mean arterial pressure among both the groups ( $P$ value 0.223 and 0.412 respectively). Attenuation of pressor responses by group E in our study matches with studies conducted by Yuan et al, Chings et al and Helfiman et al. The difference between group $\mathrm{C}$ and group $\mathrm{E}$ matches with study conducted by zulandaro MP et al in 2001 which proved clonidine was more effective than esmolol in attenuating pressor response to endotracheal intubation. 
Episodes of perioperative hypertension and tachycardia with its consequent ill effects on the vital organs can be a significant problem in some patients despite adequate depth of anaesthesia and analgesia. This study shows the effectiveness of clonidine in attenuating the increase in blood pressure following endotracheal intubation, thereby minimising significantly the imbalance between myocardial demand and supply following endotracheal intubation. Clonidine is followed by esmolol which attenuates rise in heart rate to intubation as effective as clonidine, but not as effective as clonidine in attenuating rise in blood pressure to intubation.

\section{Summary:-}

This prospective randomised study was designed to evaluate the efficacy of intravenous clonidine and esmolol in suppressing the hemodynamic changes during endotracheal intubation. A total of one hundred and twenty patients belonging to ASA 1 and 2 were randomly divided into two groups. Patients in group C received Clonidine $2 \mathrm{mcg} / \mathrm{kg}$ and in group E received esmolol $1 \mathrm{mg} / \mathrm{kg} 2$ minutes prior to induction.

The following observations were made:

1. Patients in group $\mathrm{C}$ showed the maximum attenuation of both heart rate and blood pressure following endotracheal intubation.

2. Patients in group $\mathrm{E}$ showed a significant attenuation of heart rate as effective as group $\mathrm{C}$ but attenuation of blood pressure was not as effective as group $\mathrm{C}$.

3. All the patients were recovered well from anaesthesia and none of them developed complications like severe bradycardia $(\mathrm{HR}<50 / \mathrm{min}$ ) or profound hypotension( $\mathrm{SBP}<80 \mathrm{mmHg}$ ).

\section{Conclusion:-}

From the above study it is concluded that the hemodynamic changes associated with endotracheal intubation can be safely and effectively obtunded by using intravenous clonidine prior to induction of anaesthesia.

Clonidine is found to be effective in blunting hemodynamic responses to laryngoscopy and intubation, followed by esmolol.

\section{Bibliography:-}

1. King, B.D. Harris.L.C. jr. Creifenskin. F.E. Elder. J.D and Dripps R.D(1951) - Circulatory responses to direct laryngoscopy and tracheal intubation- BJA 65: 216-219

2. Prys-Roberts, C.Green, L.T. Melochel and Foe.P. (1971)- Hemodynamic responses to laryngoscopy and intubation. BJS

3. Batra YK, Indu B.Puri GD (1988) -Attenuation of pulse rate and Blood pressure response to laryngoscopy and intubation by clonidine. Clin pharmacology Toxicol. 1988, July; 26(7): 360-63.

4. Ebert T.J.Benstein J.S.Sodwe DS, Roerig.D.(1980) Attenuation of hemodynamic responses to rapid sequence induction and intubation in healthy patients with a single bolus of esmolol J. clin. Anaesthesia 1990 Jul-Aug: 2(4): 243-52.

5. Ebert TJ (1989): circulatory changes to laryngoscopy- The comparison of placebo, fentanyl and esmolol: Can.J.Anaesth. 1989 may:36:301-06

6. Sheppards $\mathrm{S}$ et al (19so) - A bolus dose of esmolol attenuates tachycardia and hypertension after tracheal intubation: Br.J.Anaesth. 1992 May; 68(5) 529-30.

7. Vacevic M. Pordy G.M.Elid. F.R. (1902) - Esmolol hydrochloride for management of cardiovascular responses to laryngoscopy and tracheal intubation B J. Anaesth 1002 May 6s5) 529-30.

8. Fox EJSklarGS, Hill CHet al. Complications related to pressor response to endotracheal intubation. Anaesthesiology 1977:47:524-25

9. Anthony LS, James H. Edward LC. Pharmacokinetics and pharmacodynamics of esmolol administered as an intravenous bolus. Clin Pharmacol Ther 1987:41:112-17

10. Figueredo E,Garcia EM. Assessment of the efficacy of esmolol on the hemodynamic changes induced by A meta analysis. Acta Anaesthesiol Scand 2004:45:1011-22.

11. Shroff PP. Mohite SN. Panchal ID. Bolus administration of Esmolol in controlling the haemodynamic response to tracheal intubation. J Anaesth Clin Pharmacol 2004; 20 (I: 69-72

12. Ghignone M, Quintin L, Duke P.C, Kehle C.H. and Calvillo O. Effects of clonidine on narcotic requirements and haemodynamic response during induction of fentanyl anaesthesia and endotracheal intubation Anaesthesiology 1986,64: 36-42 
13. Nishikanva T. Taugchi M, Kimura T, Taguchi N Sato Y and Dai M. Effects of oral clonidine premedication upon haemodynamic changes associated with laryngoscopy and tracheal intubation Masui 1991: July 40(7) 1083-8

14. Carabine U.A, Wright P MC and Moore J. Preanaesthetic medication with clonidine: A dose response study. British Journal of Anaesthesia 1991;67;79-83

15. Laurito CE., Baughman V.L. Becker G.L., Cunningham F., Pyaon B.H. and Citron G.M.Oral clonidine blunts the haemodynamic responses to brief but not prolonged laryngoscopy. Journal Clni Anaesth. 1993, Jan-Feb 5(1)54-7.

16. Pouttu J, Scheinin B, Rosenberg PH, et al. Oral premeditation with clonidine: effects on stress responses during general anaesthesia. Acta Anaesthesiol Stand 1987:31:730-4

17. Davies DS, Wing LMH, Reid JL, et al. Pharmakokinetics and concentration-effect relationships of intravenous and oral clonidine. Clin Pharmacol Ther 1977;21:593-601

18. Orko R, Pouttu J, Ghignone M, Resenbery PH Effect of clonidine on hemodynamic responses to endotracheal intubation and on gastric acidity. Acta Anaesthesiol Stand 1987;31:325-9

19. Zalunardo M P, Zollinger A; Comparison of intravenous clonidine and esmolol for cardiovascular stress protection during induction of anaesthesia. Der Anaesthesist 50(1):21-5, 2001 Jan

20. Dipak L Raval, Malini K Mehta ; oral clonidine premedication for attenuation of hemodynamic responses to tracheal intubation Indian J Anaesth. 2002; 46 (2): 124-129 